\title{
Accelerating Progress: A New Era of Research on Character Development
}

\author{
Sarah Clement $\mathbb{D}^{1} \cdot$ Richard Bollinger ${ }^{1}$
}

Received: 30 January 2017 / Accepted: 18 April 2017 / Published online: 3 May 2017

(C) Springer Science+Business Media New York 2017

\begin{abstract}
Adolescent character development is a high priority for educators, policymakers, and front-line youth workers. To meet this growing demand, and as exemplified in the five articles in this special section, character development scholars are drawing from a range of academic disciplines to push beyond the traditional boundaries of the science of character development. These articles highlight important trends in character research, including the codevelopment of a subset of character strengths, the articulation of developmental trajectories of character, the use of advanced methodological approaches, and the implications for education. Studies such as these are critically important for establishing the research base that will be used to design the character development programs of tomorrow.
\end{abstract}

Keywords Character development ' Character education • Character strengths $\cdot$ Virtue

\section{Introduction}

The science and practice of character needs a change. To reference one popular idiom, it needs a shot in the arm. The study of an individual's character has existed in some form or another since Aristotle's writing of Nicomachean Ethics in $350 \mathrm{BC}$. Following a pattern of rising and falling interest over the intervening two millennia, "character" experienced a bit of a renaissance in the 1980s and 1990s, with scholars such as Lickona (1993) and Ryan (1989) highlighting the

Sarah Clement

sclement@templeton.org

1 John Templeton Foundation, West Conshohocken, PA, USA important role character development plays in schools, workplaces, communities, and in homes. Coupled with rising public interest in the topic (e.g. Brooks, 2015; Duckworth, 2016; Tough, 2012), there has been a tremendous demand for additional insights into how an individual—or a group of individuals - can cultivate character. Despite the early contributions of Lickona, Ryan, and others, character development and more specifically character education still suffers from a relative lack of progress. Apart from a select few, the vast majority of character education programs vary little in structure and/or function from the programs of the 1980s and 1990s. This pattern will not change unless scholars engage in research projects, like those in this special section, that challenge long-standing assumptions about character development and offer innovative solutions.

In the prototypical model, a character education program will provide time-limited resources (e.g., readings, reflection exercises) to teachers in a school, which the teachers then distribute among their students. After completing the readings and exercises, the hope is the students will improve on some-or perhaps many-dimensions of character. While there may be select instances of effectiveness for this type of model, there are many underexplored assumptions that may help explain why a program of this design is likely not demonstrating larger effects, including:

1. Framing the problem. Is it in fact the case that students simply don't know about character development and with more information they will all succeed in further cultivating character?

2. Normative development. What should we expect of $x$ character strength at $y$ age?

3. Relational nature of character. If Brooks (2016) is right, and character is cultivated in the context of close relationships, should we expect that focusing on 
any teacher-student relationship is sufficient for cultivating character? Are teacher-student relationships particularly well-suited to the development of certain kinds of character strengths?

4. Dosage. Is character something that can be cultivated in one class session? Twelve? Do all character strengths require the same amount of attention over time?

5. Community of character-How do people of good character influence others in the context of social groups?

In addition to these, there are many more unanswered questions that we have not included here. The point is that we are at an inflection point for our understanding of how character develops across the life span. By addressing these key questions and others, scholars can accelerate our understanding of both the science and practice of character.

\section{Laying the Foundation for New Research}

The five articles in this special section address topics at the forefront of our understanding, including the multidimensional nature of character, the relationship between the development of distinct character strengths, individual "profiles" of character, the developmental trajectory of specific strengths, the role of character development in education, and interventions that capitalize on the motivations that drive adolescent behavior. In many cases, the research presented here will lay the foundation for decades of future inquiry. More provocatively, several of the articles in this special section highlight the need to rethink the design of traditional character interventions. We will comment on each of the above topics in turn, closing with broader implications for the study of character in youth and adolescence.

\section{The Underlying Structure of Individual Character}

One of the fundamental questions within the study of character development is the nature of one's individual character. A robust philosophical literature on the topic exists, with many scholars following the lead set forth by Aristotle, who suggested that a person's character is comprised of moral and civic virtue (Aristotle 1999). Psychologists and educationalists, while more recent to the discussion, have been eager to identify models of character that are theoretical predicated and supported by empirical evidence. Many of these scholars can point to Lickona and Davidson's (2005) conceptualization of moral and performance character as a key starting point. In this special section, Baehr suggests a four-dimensional model of moral, civic, intellectual, and performance character. According to Baehr, these four dimensions are not mutually exclusive or exhaustive, but he does note that performance virtues are "structurally different" (p. 5) to the others. Whereas the first three are driven by intrinsic motivation for the good-the good neighbor, good citizen, and good thinker in Baehr's words-performance virtues "lack a univocal underlying motivation" (p. 3). However, performance virtues remain valuable for their usefulness, as Baehr claims, in executing an individual's intrinsically motivated goals.

Baehr's theoretical model differs from current psychological models, which often reflect a 3-dimensional model. The National Research Council (2012) for example, using the language of " $21^{\text {st }}$ Century skills," posits three domains: cognitive, interpersonal, and intrapersonal. Park and colleagues (2016) also make the case for this three-factor model, highlighting intellectual, interpersonal, and intrapersonal competences as the core components of an individual's character. Similarly, using data from the Values in Action (VIA) survey, McGrath (2015) has identified three factors he labels caring, inquisitiveness, and self-control. A notable similarity between these models, along with Baehr's, is the presence of a character strengths factor focused on the intellect, one on interacting with others, and one on self-regulation.

One clear distinction between the above models and Baehr's is the collapsing of the moral and civic factors into a single, other-focused factor. This difference highlights the failure of the psychological models to adequately address moral and civic virtue, and motivations more broadly. In part, at least for the $\mathrm{NRC}$, the omission of language around moral virtue is likely because educators have grown wary of using the terminology of morals or mortality in public schools (Lickona 2014). However, even if a three-factor model is indeed the model best supported by empirical data, the question of motivation should not be ignored, and is likely of vital importance. As Lickona (2014) noted in a recent talk, "Attention to performance character gives achievement a moral purpose: We develop our talents in order to contribute to society." Specifically, how individuals and communities internalize that moral motivation is still an open empirical question.

\section{Relationships among Character Strengths}

In Nicomachean Ethics, Aristotle (trans. 1999) proposed the concept of the "unity of the virtues," to excel in one requires excellence in all. While not making a claim as sweeping as Aristotle's, several of the articles included in this special section address how character strengths may relate to each other. In his article's conclusion, Baehr alludes to this conceptualization when he argues that directly forming intellectual virtues like humility, thoroughness, and openmindedness "better equips" students for forming moral virtue. Baehr notes that a student equipped with intellectual virtue cares deeply about knowledge, truth, and 
understanding, and is honest and open about his limitations and her duties to others. Each of these disposes a student towards moral virtues like compassion, gratitude, and forgiveness. Here, Baehr is making a theoretical assertion, one that is ripe for empirical exploration.

While the relationship between the intellectual and moral character strengths has not been explored empirically, studies examining the relationship between other character strengths are beginning to emerge. Malin et al. (2017, in this special section) directly address how purpose may relate to gratitude and compassion. The authors note that all three virtues are other-oriented, have empathy and sympathy as likely prerequisites, and result in prosocial behavior of some sort. Using cross-sectional analyses, the authors found a small but significant relationship between purpose and the other three strengths of interest: gratitude, compassion, and grit. Like Froh et al. (2010), who identified that gratitude may motivate students towards contributing to their communities, Malin et al. (2017, in this special section) identified that "qualitative differences in gratitude and compassion between those with full purpose and those who are not yet realizing their purposeful aspirations" (p. 12).

With their qualitative work, Malin and colleagues identified two findings with broader implications for the character development field. First, they identified three primary profiles of purpose/gratitude interactions with their sample (active purpose/dispositional gratitude; non-active purpose/conditional gratitude, and little purpose/little gratitude). Second, despite a small but significant correlation between grit and purpose in the quantitative data, qualitative findings in Malin et al.'s study did not indicate that purposeful students were grittier than non-purposeful students. The authors note that differences in life stage (early adolescence vs. adult) may help explain the divergent findings. These are intriguing results that begin to frame important future questions regarding how different strengths co-develop across the life span.

\section{Individual Profiles}

Interestingly, rigorous scientific studies on character development are recent enough that scholars are still working to identify not only how each character strength relates to the others on a meta-level, but also the individual trajectories of specific character strengths (e.g., Callina et al. 2017, in this special section). Perhaps even more significant than their discussion of the relationship between character strengths, Malin et al. (2017, in this special section) note,

For most people during most of development, character is far from unitary. Feelings, thoughts, and actions related to virtues may be frequently misaligned; and the virtues (or "character strengths") themselves may develop at an uneven pace, with some maturing while others grow slowly or not at all. Thus at every phase of development an individual has a distinct profile of virtues... (p. 2).

This idea of a "distinct profile of virtues," is significant for at least two reasons. First, the concept of a distinct profile aligns well with the dynamic nature of character development represented by relational developmental systems frameworks (e.g., Lerner and Callina 2014). This framework, which stands in contrast to formerly held notions of character traits as stable and immutable (e.g., Costa and McCrea 1980; 2006), emphasizes the relationship between the individual and his context, which will vary across time and place. It has become increasingly clear over the past decade that successful models of character development incorporate this dynamic perspective, with a focus on both the individual and his or her context.

Second, and relatedly, if individuals have a distinct profile of virtues at every phase of development, there are profound implications for the design and implementation of character interventions. Looking across fields, other disciplines have already made the transition from solutions based on population averages to individually-tailored approaches; this includes, but is in no way limited to precision medicine (Hudson et al. 2015), precision public health (Koury et al. 2016), and online marketing (Gilmore and Erdem 2008). These approaches seek to maximize benefit for each individual, rather than for the incredibly small proportion of the population that fit within the parameters of "average" (Rose 2016). We explore this issue in more detail below.

\section{Specifying Developmental Trajectories}

In addition to their call for a much-needed line of research that focuses on the study of the integration of character strengths, Malin et al. (2017, in this special section) agree that further research is also needed on the specification of developmental trajectories and unique contributions of specific strengths. Unfortunately, the majority of studies on character development are relatively limited in either sample size and/or the number of waves of data collection. One might think that some of the well-known longitudinal studies of development (e.g., NICHD Early Child Care Research Network 2005) could contain variables relevant to the measurement of character. While some of these large datasets do have some character-related variables (primarily as they relate to executive function and self-control), none of them contain robust assessments of an individual's character. As one potential solution to this challenge, Callina et al. (2017, in this special section) discuss the applicability of integrative data analysis (cf. Curran and Hussong 2009) to the articulation of developmental trajectories for specific character strengths. Using data from four studies with 
independent samples, the team was able to identify shared items for the assessment of hopeful future expectations. They then used these shared items as "anchors" to create a new, integrated dataset and, after fitting growth curve models to the data, established a developmental trajectory from age 7 to 26 of hopeful future expectations. As the authors note, this method provides a cost-effective means to integrate a substantial number of datasets with robust assessments of character, but limited sample size.

The dual importance of understanding both individual character development profiles and the broader developmental trajectories of specific character strengths is demonstrated in Jayawickreme, Brocato, and Blackie's study in this special section. They examine the popular maxim that adversity is a prerequisite to the formation of wisdom. They cite the popular quote "That which doesn't kill me makes me stronger" in justifying the relevance of an analysis on how particular personality characteristics relate to well-being and how, following adversity, they may contribute to the formation of growth-inducing (characterforming) vs. stagnating personal narratives. Although the researchers found primarily null results, the article identifies the centrality of the unique person-experience interaction in forming character. Even if the broad developmental trajectory of certain character strengths, like wisdom, identify certain experiential contexts, like adversity, as key components for development, Jayawickreme et al.'s (2017, in this special issue) findings identify that a large variance exists in whether and how that character strength manifested. This variance is due to the multitude of outcomes that can occur in an interaction involving the unique characteristics of the individual and the unique nature of the adverse experience (amongst many other factors). This finding emphasizes the importance of identifying both specific development trajectories of the virtues (to identify general trends) while also drawing out distinct personal profiles of virtue development (to identify meaningful between-person particularities).

\section{Moving beyond Traditional "Character Education"}

As Baehr (2017, in this special section) notes in the opening to the second part of his article, "[t]here is.... growing sense that education should be aimed at more than the transmission of knowledge, the honing of cognitive skills, or the achievement of high scores on standardized tests" (p. 5). Baehr outlines a compelling argument for organizing the educational experience around intellectual virtues such as curiosity, open-mindedness, intellectual autonomy, and intellectual humility. In his words, these "virtues have clear and central importance to academic learning" (p. 6). Critically, this model moves beyond an exclusive focus on performance character to include aspects of character development that are vital to the development of students who will contribute positively to society. "Intellectual character," Baehr writes, "is that dimension of the self or human psychology in which cognitive functioning intersects with positive character" (p. 6). As other models of character education continue to struggle with documenting effectiveness (e.g., Social \& Character Development Research Consortium 2010), scholars and practitioners alike need to reconsider the ways in which character can be seamlessly infused into the culture and curriculum of schools. Baehr's work on intellectual virtues represents an exciting potential way forward.

\section{Demand-driven Character Programs}

While some critics of character education point to the "addon" nature of the programming as a weakness in the design, and others are concerned with identifying the "right" combination of character strengths, what is often lost in the consideration is the strengths the adolescents themselves already bring to the table. In their qualitative work, Malin et al. (2017, in this special section) found that adolescents in their sample are "driven by love, respect, and worry for their families; by concern for people suffering at their schools and in their communities; by outrage at injustice; and by problems in the environment and society that they wanted to fix" (p. 12). These concerns are what motivate adolescents to cultivate character by contributing to others. Why not use these issues as a starting point?

Seider et al. (2017, in this special section) use a character lens to understand how Freire's $(1970,1973)$ concept of critical consciousness is cultivated across different high school models. Critical consciousness uses adolescents' sense of injustice as a motivating driver that leads students to engage in their communities in an effort to improve them. This perspective aligns well with what Malin et al. (2017, in this special section) identified in their own sample of students. Seider et al. (2017, in this special section) found that "the programming and practices associated with different schooling models foster particular strengths associated with critical consciousness, but simultaneously deemphasize or even weaken others" (p. 13). While the authors note that this is a preliminary conclusion, there is already an interesting follow-up question, "Is a specific focus on leveraging adolescents' sense of injustice and motivation to improve their communities more effective in cultivating character than traditional character education programs which focus on transmission of knowledge?"

\section{Conclusion}

Each of the articles in this special section offer to lay the groundwork for exciting new lines of research in character 
development. There is still much to be discovered about the nature of character development and how it is cultivated. As we noted at the outset of this article, we are at an inflection point in our understanding of character; the research in this special section are excellent examples of the ways in which we can accelerate discovery and positively influence the lives of others.

Author Contributions S.C. conceived of the initial outline of the commentary, wrote the initial draft, and oversaw final revisions. R.B. provided feedback on the initial outline, expanded the thinking and writing of several of the sections, and commented on the revisions. Both S.C. and R.B. have read the manuscript and approved its submission.

\section{Compliance with Ethical Standards}

Conflicts of Interest Both authors are employed by the John Templeton Foundation, which has provided financial support for the empirical research presented by lead authors Callina, Seider, and Malin. The Foundation has also supported theoretical work and related empirical research conducted by lead authors Baehr and Jayawickreme, respectively.

\section{References}

Aristotle. (1999). Nichomachean ethics. 2nd edn. Indianapolis, IN: Hackett Publishing Company. (T. Irwin, trans.).

Baehr, J. (2017). The varieties of character and some implications for character education. Journal of Youth and Adolescence. Advanced online publication. doi:10.1007/s10964-017-0654-z (in press).

Brooks, D. (2015). The road to character. New York, NY: Penguin Random House.

Brooks, D. (2016, October 18). The Power of a Dinner Table. The New York Times. Retrieved from http://www.nytimes.com.

Callina, K. S., Johnson, S. K., Tirrell, J. M., Batanova, M., Weiner, M. B., \& Lerner, R. M. (2017). Modeling pathways of character development across the first three decades of life: An application of integrative data analysis techniques to understanding the development of hopeful future expectations. Journal of Youth and Adolescence. Advanced online publication. 10.1007/s10964-0170660-1 (in press).

Costa, P. T., \& McCrae, R. R. (1980). Still stable after all these years: Personality as a key to some issues in adulthood and old age. In P. B. Baltes, \& O. G. Brim, Jr. (Eds.), Life span development and behavior (Vol. 3. pp. 65-102). New York, NY: Academic Press.

Costa, P. T., \& McCrae, R. R. (2006). Age changes in personality and their origins: Comment on Roberts, Walton, and Viechtbauer (2006). Psychological Bulletin, 132, 28-30.

Curran, P. J., \& Hussong, A. M. (2009). Integrative data analysis: The simultaneous analysis of multiple data sets. Psychology Methods, 14, 81-100. doi:10.1037/a0015914.

Duckworth, A. (2016). Grit: The power of passion and perseverance. New York, NY: Scribner.

Freire, P. (1970). The adult literacy process as cultural action for freedom. Harvard Educational Review, 40(2), 205-225.

Freire, P. (1973). Education for critical consciousness. New York, NY: Continuum.

Froh, J. J., Bono, G., \& Emmons, R. (2010). Being grateful is beyond good manners: Gratitude and motivation to contribute to society among early adolescents. Motivation and Emotion, 34, 144-157.
Gilmore, W., \& Erdem, S. A. (2008). The future of online internet marketing: A solution to behavioral marketing using biometrics. Journal of Business \& Economics Research, 6(2), 23-26. doi:10. 19030/jber.v6i2.2387.

Hudson, K., Lifton, R., \& Patrick-Lake, B. (2015). The Precision Medicine Initiative Cohort Program - Building a Research Foundation for 21st Century Medicine. Precision Medicine Initiative (PMI) Working Group Report to the Advisory Committee to the Director, NIH. Retrieved from https://www.nih.gov/ sites/default/files/research-training/initiatives/pmi/pmi-workinggroup-report-20150917-2.pdf on 13 Jan 2017.

Jayawickreme, E., Brocato, N. W., \& Blackie, L. E. R. (2017). Wisdom gained? Assessing relationships between adversity, personality and well-being among a late adolescent sample. Journal of Youth and Adolescence. Advanced online publication. doi:10. 1007/s10964-017-0648-x (in press).

Koury, M. J., Iademarco, M. F., \& Riley, W. T. (2016). Precision public health for the era of precision public medicine. American Journal of Preventive Medicine, 50(3), 398-401. doi:10.1016/j. amepre.2015.08.031.

Lerner, R. M., \& Callina, K. S. (2014). Relational developmental systems theories and the ecological validity of experimental designs. Human Development, 56(6), 372-380.

Lickona, T. (1993). The return of character education. Educational Leadership, 51(3). Available online: www.ascd.org/readingroom/ edlead/9311/lickona.html.

Lickona, T. (2014). "My 45-Year Journey as a Moral and Character Educator: Some of What I Think I've Learned," an invited lecture at the Jubilee Centre for Character and Virtues. England: University of Birmingham. June 25.

Lickona, T., \& Davidson, M. (2005). Smart and good high schools: Integrating excellence and ethics for success in school, work, and beyond. Cortland, NY: Center for the 4th and 5th Rs (Respect and Responsibility). Washington, DC: Character Education Partnership.

Malin, H., Liauw, I., \& Damon, W. (2017). Purpose and character development in early adolescence. Journal of Youth and Adolescence. Advanced online publication. doi:10.1007/s10964-0170642-3 (in press).

McGrath, R. (2015). Integrating psychological and cultural perspectives on virtue: The hierarchical structure of character strengths. The Journal of Positive Psychology, 10(5), 407-424.

National Research Council. (2012). Education for life and work: Developing transferable knowledge and skills in the 21 st century. committee on defining deeper learning and 21 st century skills, In J. W. Pellegrino, \& M. L. Hilton, (Eds.), Board on testing and assessment and board on science education, division of behavioral and social sciences and education. Washington, DC: The National Academies Press.

NICHD Early Child Care Research Network. (2005). Child care and development: Results from the NICHD study of early child care and youth development. NY: Guilford Press.

Park, D., Tsukayama, E., Goodwin, G., Patrick, S., \& Duckworth, A. (2016). A tripartite taxonomy of character: Evidence for intrapersonal, interpersonal, and intellectual competencies in children. Contemporary Educational Psychology. doi:10.1016/j.cedpsych. 2016.08.001.

Rose, T. (2016). The end of average. NY: HarperCollins.

Ryan, K. (1989). In defense of character education. In L. P. Nucci (Ed.). Moral Development and Character Education: A dialogue (pp. 3-18). Berkeley: McCutcheon..

Seider, S., Tamerat, J., Clark, S., \& Soutter, M. (2017). Investigating adolescents' critical consciousness development through a character framework. Journal of Youth and Adolescence. 
Advanced online publication. doi:10.1007/s10964-017-0641-4 (in press).

Social and Character Development Research Consortium. (2010). Efficacy of schoolwide programs to promote social and character development and reduce problem behavior in elementary school children (NCER 2011-2001). Washington, DC: National Center for Education Research, Institute of Education Sciences, U.S. Department of Education.

Tough, P. (2012). How children succeed: Grit, curiosity, and the hidden power of character. Boston: Houghton Mifflin Harcourt.
Sarah Clement is the Director of Character Virtue Development at the John Templeton Foundation. Her major research interests include: character development, positive youth development, systems evaluation, stress, and health.

Richard Bollinger is the Program Officer for Character Virtue Development at the John Templeton Foundation. His major research interests include: character development, positive psychology, religion and spirituality, and evidence-informed psychotherapy practices. 